\title{
Considerações sobre o papel da consciência morfológica nas dificuldades de leitura e escrita: uma revisão da literatura
}

\author{
Consciência morfológica
}

\author{
Márcia Elia da Mota
}

\begin{abstract}
Resumo
Este trabalho teve como objetivo revisar a produção científica nacional e internacional indexada no Scielo e no periódico CAPES (Web of Science e Psychinfo), entre 1996 e 2006 sobre a relação entre a consciência morfológica e as dificuldades de aprendizagem da leitura e escrita. Foram selecionados estudos empíricos que descreviam o relacionamento entre a consciência morfológica e a alfabetização. Identificaram-se 16 artigos (três nacionais e 13 internacionais) que foram analisados considerando os seguintes aspectos: a relação causal entre a consciência morfológica e a alfabetização e o papel da consciência morfológica nas dificuldades de leitura e escrita. Foi feita uma análise dos periódicos em que foram publicados tipos de técnicas de coleta e análise de dados utilizados. Os resultados apontam para a carência de estudos empíricos que estudem este fenômeno no Brasil. São discutidas também as implicações teórico-metodológicas destes estudos para o contexto educacional e para avaliação das dificuldades de leitura.
\end{abstract}

Palavras-chave: Morfologia, Metalinguagem, Alfabetização.

\section{Considerations about the role of morphological awareness in reading and spelling difficulties: a literature review}

\begin{abstract}
The objective of this work was to revise the national and international scientific production indexed in the Scielo and the periódico CAPES (Web of Science and Psychinfo), between 1996 and 2006 on the relation between morphological awareness, reading and spelling difficulties. Empirical studies had been selected that described the relationship between morphological awareness and literacy. It has been identified 16 articles (three national and 13 international ones) that were analyzed considering the following aspects: the causal relation between morphological awareness and literacy, and the role of morphological awareness in reading and spelling difficulties. An analysis of the articles and where they had been published, types of techniques of collection and analysis of data were made. The results point out to the lack of empirical studies that study this phenomenon in Brazil. The theoretical and methodological implications of these studies for the educational context and for the evaluation of the reading difficulties are also discussed.

Keywords: Morphology, Metalinguistics, Literacy.

\section{Consideraciones sobre el papel de la consciencia morfológica en las dificultades de lectura y escrita: una revisión de la literatura}

\begin{abstract}
Resumen
Este trabajo tuvo como objetivo revisar la producción científica nacional e internacional indexada en Scielo y en la revista CAPES (Web of Science e Psychinfo), entre 1996 y 2006 sobre la relación entre la consciencia morfológica y las dificultades de aprendizaje de lectura y escrita. Fueron seleccionados estudios empíricos que describían la relación entre la consciencia morfológica y la alfabetización. Se identificaron 16 artículos (tres nacionales y 13 internacionales) que fueron analizados considerando los siguientes aspectos: la relación causal entre la consciencia morfológica en las dificultades de lectura y escrita. Fue realizado un análisis de las revistas en las cuales fueron publicados tipos de técnicas de cosecha y análisis de datos utilizados. Los resultados apuntan una carencia de estudios empíricos que investiguen ese fenómeno en el Brasil. También son discutidas las implicaciones teórico-metodológicas de estos estudios para el contexto educacional y para la evaluación de las dificultades de lectura.

Palabras clave: Morfología, Metalenguaje, Alfabetización.
\end{abstract}




\section{Introdução}

Nos últimos 30 anos observou-se um aumento expressivo do número de estudos que investigaram a relação entre a consciência metalingüística e a alfabetização (ver Gombert, 1992 para uma revisão). Dentre as habilidades metalingüísticas três se destacam por contribuírem de forma causal para o sucesso na alfabetização: a consciência fonológica, a consciência sintática e a consciência morfológica.

Das três habilidades mencionadas, a mais estudada é a consciência fonológica, que pode ser definida como a habilidade de refletir sobre os sons que compõem a fala (Cardoso-Martins, 1995). Estudos demonstram que a consciência fonológica ajuda na alfabetização, e que o treinamento desta habilidade ajuda na remediação dos problemas de leitura (ver Goswami \& Bryant, 1990 para uma revisão). No Brasil os trabalhos de Capovilla e Capovilla (2000), Cardoso-Martins (1995), Guimarães (2003), Maluf e Barrera (1997), e Santos (1996), só para citar alguns, confirmam a importância do tema para aquisição da língua escrita no português brasileiro.

No entanto, como já referido, a consciência fonológica não é a única habilidade a facilitar o processo de alfabetização. Um novo corpo de evidência vem se formando, apontando para o papel facilitador da consciência morfológica na aquisição da leitura e escrita (Carlisle, 1988, 1995, 2000).

A habilidade de refletir sobre os morfemas, menores unidades lingüísticas que tem significado próprio, é chamada consciência morfológica (Carlisle, 1995). Esta habilidade pode ajudar na alfabetização porque a ortografia de muitas palavras depende da morfologia. Palavras, como "laranjeira", que têm ortografia ambígua podem ser escritas de forma correta se for conhecida sua origem: "laranja". Os significados delas podem ser igualmente inferidos na leitura, sabendo-se o significado da palavra que as originou.

Mann (2000) aponta duas razões pela qual o processamento morfológico é importante para leitura. A primeira diz respeito à argumentação já apresentada de que a escrita pode ser analisada em vários níveis, não só o fonológico. Um destes níveis é o semiográfico, no qual se estabelece a compreensão dos grafemas na representação dos significados das palavras (MarecBreton \& Gombert, 2004). A consciência morfológica facilitaria a aquisição do princípio semiográfico.

A segunda razão seria mais específica à natureza da ortografia estudada. A argumentação principal para explicar a relação encontrada entre o processamento morfológico e a alfabetização vem de pesquisas realizadas em falantes do inglês, língua nativa de Mann, e diz respeito à natureza da ortografia inglesa.
O princípio alfabético é o de que letras devem corresponder perfeitamente aos sons das palavras, mas as línguas alfabéticas variam quanto ao grau de correspondência entre as letras e os sons da fala. No inglês essas relações são mais opacas do que em ortografias como o finlandês, o português ou o espanhol. Muitas das irregularidades encontradas no inglês podem ser explicadas pela estrutura morfológica das palavras (Chomsky \& Halle, 1968; Sterling, 1991). Por exemplo, no inglês a palavra 'heal' que rima com 'il' e a palavra 'health' que rima com 'elf' têm a mesma origem semântica por isso são escritas da mesma forma, embora sejam pronunciadas de forma diferente.

Nas línguas com ortografias mais regulares 0 processamento morfológico pode não contribuir de forma significativa para aquisição e processamento da língua escrita, porque a maioria das palavras pode ser escrita aplicando-se o princípio alfabético. Lehtonen e Bryant (2005) ressaltam que embora este seja um argumento válido, a hipótese de que a consciência morfológica contribui para alfabetização nestas ortografias regulares também é pertinente. Os autores consideram que esta é uma questão teórica que precisa ser mais bem investigada.

Mann (2000) supõe que as línguas alfabéticas mais regulares podem ser mais dependentes da estrutura fonológica das palavras do que da estrutura morfológica. De fato, no inglês, em uma série de estudos que visavam explorar a relação entre a consciência morfológica e a alfabetização, Joanne Carlisle mostrou que a habilidade de refletir sobre os morfemas das palavras estava associada ao desempenho na leitura de palavras isoladas e à compreensão de leitura (Carlisle, 1995, 2000; Carlisle \& Fleming, 2003), e também ao desempenho da escrita (Carlisle, 1988, 1996). O problema com estes estudos é que a consciência fonológica não foi controlada.

Alguns autores argumentam que a consciência morfológica não contribui de forma independente para alfabetização (Bowey, 2005; Fowler \& Liberman, 1995) e é um subproduto do processamento fonológico. Embora, este não seja o foco desta pesquisa, esta é uma questão importante, pois traz implicações pedagógicas e também para avaliação das dificuldades de aprendizagem.

Além disso, a questão levantada por Mann (2000) e Lehtonen e Bryant (2005) a respeito da natureza da ortografia precisa ser considerada. No português, uma língua alfabética mais regular do que 0 inglês, há evidências de uma relação entre a consciência morfológica e desempenho na escrita (Mota, 1996; Queiroga, Lins \& Pereira, 2006; Rego \& Buarque, 1997), e na leitura (Mota, Annibal \& Lima, no prelo). Isto ocorre provavelmente porque, apesar de o português ser uma língua regular há muitas ocasiões em que a morfologia pode ajudar na escolha da grafia correta das palavras (por exemplo, nos 
pares de palavras 'marcaram' e 'marcarão'; 'beleza' e 'princesa'). Entretanto, estudando o finlandês, uma língua onde não se encontra este tipo de ambigüidade, Lehtonen e Bryant (2005) encontraram uma contribuição menos específica da consciência morfológica para escrita. Os resultados destes autores indicam que o tipo de ortografia tem uma influência no papel da consciência morfológica na escrita.

Se a consciência morfológica contribui de forma independente para a aquisição da leitura e escrita, então programas de intervenção focados neste tipo de habilidade podem contribuir para a remediação dos problemas de aprendizagem da leitura e escrita. Por outro lado, se a consciência morfológica não contribui de forma independente para leitura e escrita, então programas de intervenção devem enfatizar primariamente a melhoria do processamento fonológico da criança.

O papel da consciência morfológica no processamento da língua escrita no português ainda é pouco explorado. Este trabalho trata de uma pesquisa bibliográfica focou nos estudos que mostram uma relação causal entre o processamento morfológico e a escrita e as implicações para os problemas de aprendizagem.

\section{Método}

\section{Fonte}

Verificou-se a freqüência de artigos publicados no período de 10 anos (1996 a 2006) em revistas indexadas na base de dados Periódicos CAPES (Psychinfo e Web of science) e Scielo sobre a relação entre o processamento morfológico e a alfabetização.

\section{Procedimento}

Foram utilizados como descritores as palavras "morphological awareness and reading", "morphological awareness and spelling", "syntactic awareness and reading" e "syntactic awareness and spelling" para as bases de dados internacionais. Para a base de dado nacional (Scielo), devido à tradição de pesquisa nacional que muitas vezes trata o termo "consciência morfológica" como sinônimo de "consciência sintática", utilizou-se os termos "consciência morfológica", "consciência metalingüística", "consciência sintática" e "ortografia". Foram selecionados 16 textos que envolviam o estudo da relação entre a consciência morfológica e a aquisição da leitura ou processamento morfológico e aquisição da escrita. Esses termos, embora indicassem algumas vezes artigos que não se relacionavam diretamente ao tema (processamento morfológico e envelhecimento, processamento sintático em crianças bilíngües, desenvolvimento ortográfico) permitiram a obtenção de uma amplitude maior de artigos sobre o assunto tratado. Foram excluídos artigos de revisão da literatura (apenas encontrados na base de dados nacional), artigos que tratavam da consciência sintática sem focar nos aspectos morfossintáticos ou da morfologia derivacional, capítulos de livro ou livros que constavam na lista obtida a partir destes termos-chave, e artigos que tratavam de assuntos não diretamente ligados ao tema como os já citados.

\section{Resultados}

Os resultados são apresentados em três partes: na primeira parte foi feita uma descrição das fontes de informação utilizadas, na segunda parte fez-se uma revisão dos estudos que vinculam a consciência morfológica com a alfabetização, e por fim foram apresentados os estudos realizados com crianças com dificuldades de aprendizagem.

\section{Análise das fontes de informação}

Essa pesquisa bibliográfica resultou em um levantamento de textos que tratavam de aspectos do desenvolvimento do processamento morfológico, como diferenças na aprendizagem de tipos de morfemas e estudos comparativos entre diversas ortografias. Para delimitar a presente revisão, dentre estes foram priorizados, já que o tema tratado diz respeito às dificuldades de leitura e escrita. Os textos de pesquisas que ofereciam evidência para a relação entre 0 processamento morfológico e o desenvolvimento da leitura e escrita. Do total foram selecionados 03 artigos nacionais e 13 internacionais.

Cabe ressaltar que essa pesquisa bibliográfica enfocou apenas crianças que se encontram no ensino regular e que não são portadoras de necessidades especiais (como por exemplo, crianças com perdas auditivas, ou problemas na aquisição da linguagem que não fossem a dislexia). Para contextualizar os resultados apresentados, textos clássicos anteriores a 1996 algumas vezes foram incluídos na discussão dos resultados. Observou-se que a inclusão destes textos não compromete uma visão do panorama das tendências na análise de dados e questões centrais tratadas nos últimos dez anos pelas pesquisas no tema abordado.

Comparando a produção científica nacional e internacional observou-se a necessidade de uma quantidade maior de estudos nesta área no Brasil. No Brasil apenas dois artigos enfocaram especificamente a relação entre a morfologia e a escrita. Apresentar-se-á a seguir uma análise dos tipos de técnicas de análise e coleta de dados utilizados nos artigos, bem como uma análise dos periódicos onde os artigos foram encontrados. Depois, serão apresentados os principais resultados dos estudos levantados nesta pesquisa bibliográfica. 


\section{Técnica de coleta e análise de dados}

Todos os artigos pesquisados envolviam estudos empíricos: observação sistemática, estudos experimentais ou estudos longitudinais utilizando técnicas de análise multivariada de dados. Usavam como técnica de coleta de dados tarefas experimentais que envolviam a avaliação da consciência morfológica ou a avaliação da leitura e escrita, além dos controles usuais das habilidades cognitivas das crianças através de testes padronizados. Só foram encontrados três artigos nacionais sobre o tema. Dois artigos publicados na revista Psicologia: Reflexão e Crítica e um na revista Psicologia: Teoria e Pesquisa. A Tabela 1 mostra a lista de periódicos internacionais e o número de artigos encontrados por periódicos. A Tabela 2 mostra 0 tipo de delineamento experimental utilizado.

\section{Principais resultados dos estudos que investigam a relação entre Consciência Morfológica e alfabetização}

Estudos, em várias ortografias, mostram uma associação entre a consciência morfológica e a alfabetização (Carlisle, 1996, 2000; Carlisle \& Fleming, 2003; Lehtonen \& Bryant, 2005; Plaza \& Cohen, 2003, 2004). Esses estudos demonstram que mesmo em línguas com ortografias alfabéticas a consciência morfológica contribui para leitura e escrita. Porém, essa contribuição pode não ser específica.

Dois modelos são apresentados para estabelecer a relação entre o papel específico do processamento morfológico na aquisição da língua escrita. O primeiro modelo, chamado de modelo unitário, considera que o processamento morfológico/sintático é produto do processamento fonológico, tendo papel secundário na aquisição da leitura e escrita. O segundo modelo considera que embora o processamento fonológico tenha um papel de maior importância que 0 processamento morfológico/sintático na escrita, a contribuição das últimas habilidades para alfabetização é independente da fonológica. Mostrar que a consciência morfológica contribui de forma específica para leitura e escrita indica que essa habilidade ajuda a alfabetização e pode ser uma das causas das dificuldades na leitura e escrita.

Em um estudo longitudinal Plaza e Cohen $(2003,2004)$ testaram os modelos acima. Os autores investigaram o papel preditivo da consciência fonológica, consciência sintática/morfossintática e velocidade de nomeação na alfabetização de crianças de seis a sete anos de idade falantes do francês.

Para avaliar a consciência sintática/morfossintática os autores usaram tarefas de julgamento e correção da gramaticalidade de sentenças. Os resultados mostraram que as três habilidades contribuíram de forma independente para aquisição da alfabetização. Como esperado a habilidade que mais contribuiu para a alfabetização foi a consciência fonológica, seguida pela velocidade de nomeação. O terceiro melhor preditor do sucesso na alfabetização foi a consciência morfossintática. O resultado mais importante deste estudo foi o de que, apesar de não ser o melhor preditor da alfabetização, a consciência sintática/morfossintática continuou contribuindo de forma independente para o processamento da escrita, mesmo depois de terem sido controladas a consciência fonológica e a velocidade de nomeação.

Tabela 1. Distribuição de freqüência do número de artigos em periódicos Internacional.

\begin{tabular}{lc}
\hline \multicolumn{1}{c}{ Periódicos } & Freqüência \\
\hline Annals of Dyslexia & 1 \\
Applied Psycholinguistics & 2 \\
Brain and Cognition & 2 \\
Developmental Psychology & 1 \\
Journal of Educational Psychology & 2 \\
Journal of Experimental Child Language & 1 \\
Reading and Writing & 2 \\
Reeducation Orthophonic & 1 \\
Scientific studies of Reading & 1 \\
\hline Total & 13 \\
\hline
\end{tabular}


Tabela 2. Distribuição de freqüência do número de tipos de delineamentos usados nos artigos em periódicos Internacional.

\begin{tabular}{lc}
\hline \multicolumn{1}{c}{ Tipo de Delineamento } & Freqüência \\
\hline Estudos longitudinais com análises multivariadas & 5 \\
Estudos transversais com técnicas multivariadas & 2 \\
Observação sistemática ou estudos experimentais & 6 \\
\hline
\end{tabular}

Bowey (2005) também testou os dois modelos citados através de um estudo longitudinal. A autora argumenta que estudos que mostram a contribuição independente da sensibilidade à sintaxe da língua para alfabetização, em geral utilizam critérios pouco conservadores de controle de variáveis. No estudo de Bowey as tarefas utilizadas muitas vezes envolviam aspectos morfossintáticos. Embora os aspectos mais globais do processamento sintático das sentenças estivessem confundidos com aspectos morfológicos, o estudo de Bowey levanta questões importantes que merecem ser considerados aqui.

Aceita-se que haja uma interação entre 0 desenvolvimento metalingüístico e a alfabetização. Algum grau de consciência metalingüística é necessário para se apreender a ler e a escrever, mas a experiência com a escrita ajuda a desenvolver essa habilidade (Gombert, 2003). Ao se estudar o valor preditivo das habilidades metalingüísticas para leitura é importante que se controle 0 conhecimento inicial da leitura. Bowey (2005) argumenta que os estudos sobre o assunto incluem crianças com conhecimento rudimentar da língua escrita e as tratam como não leitores, para Bowey isto acaba por aumentar artificialmente 0 efeito da consciência sintática/morfossintática no desempenho da leitura.

Usando um critério mais conservador Bowey (2005) deu a crianças de quatro anos de idade, não leitoras uma série de tarefas cognitivas, de processamento fonológico e de julgamento e correção de sentenças. Os resultados de Bowey mostraram que as tarefas de consciência sintática/morfossintática não contribuíram de forma independente para leitura e escrita, mas as tarefas de consciência fonológica sim.

Nunes, Bryant e Bindman (1997) concordam que o desenvolvimento da consciência morfológica ocorre tardiamente no desenvolvimento. Através de um estudo longitudinal, os autores mostraram que as crianças parecem passar por uma seqüência de estágios no seu entendimento de como as palavras morfologicamente complexas são formadas. Os autores que estudaram a aquisição da escrita de morfemas como o "ed" no inglês, argumentam que antes que as crianças possam escrever palavras morfologicamente complexas, que fogem os padrões de correspondência entre letra e som do inglês, elas precisam ter entendido o princípio alfabético.

O resultado do estudo de Nunes e cols. está de acordo também com os principais modelos de desenvolvimento da escrita que trabalham com a idéia de desenvolvimento em estágios e de que o processamento das palavras em morfemas ocorre após a aquisição do princípio alfabético (Frith, 1985; Marsh, Friedman, Welsh \& Desberg, 1980).

No entanto, é possível que o desenvolvimento da escrita possa não ocorrer em estágios e que também não seja necessário que as crianças tenham adquirido o princípio alfabético antes de usar informações morfológicas. Estudos posteriores ao de Nunes, Bryant e Bindman (1997) têm mostrado que as crianças se beneficiam da morfologia da língua desde cedo no processo de alfabetização.

Deacon e Kirby (2004), por exemplo, defendem que a contribuição da consciência morfológica para a leitura é independente da consciência fonológica. Para testar este modelo, Deacon e Kirby realizaram um estudo longitudinal que durou quatro anos, iniciando com crianças de primeira série. Neste estudo os autores mostraram que a consciência morfológica contribuiu para os escores de leitura em todas as tarefas apresentadas (leitura de palavras simples, pseudopalavras e compreensão da leitura), e esta contribuição foi independente da contribuição da consciência fonológica.

Um resultado importante do estudo de Deacon e Kirby (2004) é que as crianças investigadas, embora não tão novas quanto às do estudo de Bowey (2005), estavam na primeira série. De acordo com os modelos de Marsh e cols. (1980), Frith (1985) e Nunes e cols. (1997) as crianças ainda deveriam estar presas ao processamento fonológico e na aquisição do princípio alfabético na escrita.

Um outro estudo que defende a contribuição independente da consciência morfológica para escrita foi realizado por Nagy, Berninger e Abbot (2006), mas este estudo foi feito com crianças mais velhas.

Os autores deram a crianças americanas de quarta série até a nona série (equivalente ao segundo ano do ensino médio no Brasil) tarefas de consciência morfológica, fonológica, leitura de palavras, compreensão de leitura, decodificação de palavras morfologicamente complexas, e tarefa de escrita de palavras isoladas. Os resultados do estudo de Nagy e cols. (2006) mostram que a contribuição da consciência morfológica foi independente da fonológica para todas as tarefas de processamento da leitura e escrita.

Resultados semelhantes foram encontrados no francês Colé, Marec-Breton, Royer e Gombert (2003) que 
estudaram crianças francesas nos anos iniciais da aprendizagem da leitura. No estudo de Colé e cols. as crianças tinham que ler quatro grupos de palavras: palavras morfologicamente complexas (ex., 'banheiro' 'banho'+'eiro'); palavras com a mesma seqüência de letras, mas morfologicamente simples (ex., 'dinheiro'); pseudopalavras morfologicamente complexas (ex., 'linheiro' - 'linho'+'eiro'); pseudopalavras não sufixadas (ex., 'binheiro').

Apesar das palavras no estudo e Cole e cols. (2003) terem as mesmas características fonológicas e número de letras, as crianças cometeram menos erros lendo as palavras morfologicamente complexas do que as palavras simples. Estes resultados indicam um efeito facilitador da estrutura morfológica no reconhecimento de palavras.

Se a consciência morfológica contribui para leitura e escrita de forma independente como sugerem estes estudos, práticas pedagógicas que desenvolvam esta habilidade podem beneficiar o processo de alfabetização. Da mesma forma, o diagnóstico precoce dos problemas no processamento morfológico pode auxiliar na implementação de intervenções que possam prevenir problemas futuros na aprendizagem da leitura e da escrita.

No português, com exceção do estudo de Guimarães (2003), estudos que demonstraram a relação entre a consciência morfossintática e o desempenho ortográfico (Queiroga \& cols., 2006; Rego \& Albuquerque, 1997) não verificaram se o conhecimento morfológico contribui para a escrita e para a leitura de modo geral, mas estes estudos mostraram uma contribuição da consciência morfossintática para a escrita de palavras ortograficamente complexas.

Faltam estudos que investiguem o papel do processamento da morfologia derivacional no português. Além disso, considerando que o português é uma língua com ortografia transparente é importante investigar melhor o papel da consciência morfológica e fonológica para alfabetização.

Para responder algumas destas perguntas Mota e cols. (no prelo) deram a crianças de primeira e segunda série tarefas de consciência morfológica focando a morfologia derivacional, consciência fonológica e as tarefas de leitura e escrita do Teste de Desempenho Escolar. Várias das tarefas de consciência morfológica correlacionaram com o desempenho na leitura e na escrita. Além disso, os escores da tarefa de analogia gramatical contribuíram para a leitura e escrita em geral (escores no Teste de Desempenho Escolar) independente da consciência fonológica.

De um modo geral estes estudos sugerem que o conhecimento morfológico contribui para a compreensão da formação das palavras e por sua vez ajudam na leitura e na escolha da ortografia correta. Se este é o caso a consciência morfológica pode contribuir para remediação das dificuldades na leitura e na escrita. Os estudos que descreveremos a seguir tratam deste assunto.

\section{Estudos com crianças com dificuldades de Aprendizagem}

Há bastante consenso entre pesquisadores que dificuldades no processamento fonológico explicam boa parte dos problemas de aprendizagem na leitura. Recentemente o papel da consciência morfológica se apresenta como uma outra habilidade que contribui de forma independente para leitura e escrita.

Embora os estudos sobre o desenvolvimento da consciência morfológica com crianças com dificuldades de aprendizagem no ensino regular sejam ainda pouco numerosos, alguma evidência de que o processamento morfológico contribui para as dificuldades de aprendizagem da leitura foram encontradas.

Carlisle, Stone e Katz (2001) deram a crianças de dez a quinze anos de idade duas tarefas de leitura que envolviam dois grupos de palavras derivadas. O primeiro grupo de palavras eram palavras derivadas nas quais não havia mudanças na pronuncia da palavra base e da palavra derivada ("cultural" e "culture"), o segundo grupo envolvia palavras nas quais havia diferenças na pronuncia ("natural" e "nature"). Os pares de palavras eram comparáveis quanto: à freqüência de ocorrência, número de letras e padrão ortográficos. Desta forma, os autores argumentam que qualquer diferença na leitura destes dois grupos de palavras só poderia ser atribuída ao processamento morfológico.

As palavras que não têm mudanças fonológicas na leitura seriam mais fáceis, pois estabelecer a relação entre a base da palavra e a palavra morfologicamente complexa fica simplificado. No caso das palavras onde há mudanças na pronúncia só conhecer a base não garante a pronúncia correta, a criança precisa entender que tipo de mudança fonológica ocorreu.

As crianças foram divididas em dois grupos: bons e maus leitores. Os resultados mostraram que as palavras sem alteração fonológica foram mais fáceis de ler e reconhecer do que as palavras com mudanças. No entanto, a diferença entre a leitura dos dois grupos de palavras foi mais marcada para os maus leitores.

Carlisle e cols. (2001) concluíram que a dificuldade dos maus leitores em ler as palavras com mudanças fonológicas está relacionada a uma dificuldade no processamento fonológico complexo das palavras morfologicamente complexas. Os autores sugerem, parte desta dificuldade está no entendimento das relações morfológicas entre as palavras, e que trabalhando com as crianças a relação entre a base dos morfemas e seus derivados, e as mudanças que certos derivados sofrem, pode ajudá-los a mais rapidamente decidir a pronúncia 
correta das palavras e fazer decisões a respeito da grafia destas palavras também.

Cabe ressaltar aqui que a dificuldade encontrada pelas crianças no estudo citado envolve mais diretamente o processamento fonológico. Opina-se que esta sugestão de Carlisle e Fleming (2003) pode levar as crianças a simplesmente decorar as palavras. Seria preciso demonstrar que o conhecimento da relação morfêmica entre as palavras ajudaria a leitura mais eficaz destas palavras. Isto é, se o conhecimento da relação morfêmica entre as palavras facilita a leitura e escrita, e se está associada a dificuldades especificas a aquisição destas habilidades.

Nagy, Berninger e Abbot (2003) avaliaram a contribuição do conhecimento fonológico, ortográfico, morfológico e do vocabulário para crianças de segunda série com dificuldades de leitura e crianças de quarta série com dificuldades na escrita. Para as crianças de segunda série a contribuição do processamento morfológico foi significativa para a compreensão de leitura, e apenas o conhecimento ortográfico e o vocabulário contribuíram para leitura de palavras isoladas. Já para as crianças de quarta série nenhuma das medidas contribuiu de forma significativa para leitura ou escrita. No entanto, a correlação simples entre consciência morfológica e a leitura de palavras isoladas foi significativa. Estes resultados sugerem que crianças em risco de apresentarem problemas na leitura se beneficiam da consciência morfológica para compreender os textos lidos.

Os autores argumentam que embora não se tenha observado uma contribuição da consciência morfológica para escrita das crianças da quarta série com dificuldades, as correlações mostram que o conhecimento da morfologia está associado à leitura e à escrita. De fato, em um estudo posterior, Nagy e cols. (2006) mostram a contribuição específica da morfologia para o desempenho na leitura e na escrita de crianças no ensino regular.

Assim, para os autores práticas de ensino devem envolver o desenvolvimento desta habilidade. Nagy e cols. (2003) sugerem que estas práticas não devem envolver decorar listas de palavras descontextualizadas, mas sim refletir sobre a estrutura interna das palavras, seu significado e o contexto que aparecem nas frases. Essa reflexão sobre a estrutura interna das palavras pode incluir uma reflexão sobre a fonologia também e sua relação com os processos de derivação e flexão das palavras.

No português encontramos um único estudo que trabalhou com comparações entre bons e maus leitores. Guimarães (2003) investigou a contribuição da consciência sintática (as tarefas envolviam aspectos morfossintáticos) e fonológica para escrita de crianças com dificuldades de aprendizagem. As crianças no estudo de Guimarães estavam na terceira e quarta séries do Ensino Fundamental. Comparações feitas entre a performance das crianças com dificuldade de aprendizagem com controles mais novos, que apresentavam o mesmo nível de leitura mostraram um déficit no processamento fonológico das crianças com dificuldades de aprendizagem, mas nenhuma diferença estatisticamente significativa entre os grupos nas tarefas de consciência sintática.

Estes resultados sugerem que não há relação causal entre as dificuldades de leitura e a consciência sintática no português. O português como já levantamos é uma língua mais regular em termos das correspondências entre letra e som que o inglês. É possível que as dificuldades de leitura no português estejam mais associadas ao processamento fonológico do que ao morfológico.

No entanto, estudos correlacionais têm identificado uma correlação significativa e positiva entre 0 processamento morfológico e a escrita em português e também com a leitura (Mota \& cols., no prelo). Assim, mais estudos são necessários para se estabelecer a contribuição do processamento morfológico para as dificuldades de leitura e escrita de crianças falantes do português.

\section{Considerações Finais}

O resultado desta pesquisa bibliográfica ressalta dois pontos importantes que devem ser considerados por pesquisadores interessados no estudo dos processos metalingüísticos e da alfabetização, em particular o papel do processamento morfológico e a escrita. Em primeiro lugar a maioria (10 em 13) dos artigos pesquisados foi realizada em língua inglesa. Apenas três foram realizados no português. Em segundo lugar a relação entre consciência morfológica e dificuldades na aquisição da escrita ainda não está totalmente estabelecida. Faltam estudos de intervenção que possam estabelecer a relação causal entre essa habilidade e a escrita, e também, estudos que demonstrem a eficácia de intervenções que desenvolvam essas habilidades.

De um modo geral estudos com crianças em ensino regular mostram uma relação causal entre a consciência morfológica e aquisição da língua escrita (Deacon \& Bryant, 2004; Nagy \& cols., 2006; Plaza \& Cohen, 2004). Entretanto, esses resultados não foram corroborados de forma efetiva pelos estudos focando crianças com dificuldades na aprendizagem da leitura e da escrita. Parte do problema se encontra na metodologia utilizada pelos últimos.

Estudos de intervenção são necessários para que seja possível estabelecer esta relação causal. Cabe ressaltar que estudos experimentais de intervenção utilizados para estabelecer relações causais entre habilidades, nem sempre são adequados para aplicação educacional (ver 
Goswami \& Bryant, 1990 para uma discussão). Assim, as pesquisas sobre a relação entre 0 processamento morfológico e alfabetização precisam focar em duas questões principais: Existe uma relação causal entre consciência morfológica e escrita? Como traduzir para o cotidiano escolar, práticas que desenvolvam 0 processamento morfológico?

Recentemente Nunes e Bryant (2006) realizando tanto estudos de intervenção no laboratório, quanto no contexto educacional concluíram que é importante se ensinar a respeito de como as palavras são formadas por morfemas. No Brasil, não encontramos estudos de intervenção que investiguem este fenômeno, e a questão da relação causal entre o processamento morfológico e a escrita ainda precisa ser mais bem estudada.

$\mathrm{Na}$ avaliação das dificuldades de aprendizagem esta questão também permanece aberta. Embora a avaliação da consciência fonológica já venha sendo incorporada ao diagnóstico das dificuldades de aprendizagem, o valor da avaliação de outros aspectos do desenvolvimento cognitivo que vêm sendo apontados na literatura, como estando relacionados com a alfabetização de forma causal, como a velocidade de nomeação (Guaraldo, 2006) e o processamento morfológico precisam ser mais bem avaliados.

Uma última consideração precisa ser feita quanto à técnica de análise de dados. A análise de dados multivariada utilizada em estudos longitudinais foi freqüentemente usada. Este tipo de delineamento favorece uma melhor compreensão dos processos de desenvolvimento humano, pois permite acompanhar a evolução do desenvolvimento ao longo do tempo, sugerindo que seja incorporado aos delineamentos experimentais de pesquisas realizadas no Brasil com mais freqüência.

\section{Referência}

Bowey, J. (2005). Grammatical sensitivity: its origins and potential contribution to early reading skill. Journal of Experimental Child psychology, 90, 318-343.

Capovilla, A., \& Capovilla, F. (2000). Efeitos do treino de consciência fonológica em crianças com baixo nível sócioeconômico. Psicologia: Reflexão e Crítica, 13(1), 07-24.

Cardoso-Martins, C. (Org.). (1995). Consciência fonológica e alfabetização. Petrópolis: Vozes.

Carlisle, J. (1995). Morphological awareness and early reading achievement. Em L. Feldman (Org.), Morphological aspects of language processing (pp.189-211). Hillsdale: Lawrence Erlbaum Associates.
Carlisle, J. (1996). An exploratory study of morphological errors in children's written stories. Reading and Writing: an Interdisciplinary Journal, 8, 61-72.

Carlisle, J. (1988). Knowledge of derivational morphology and spelling ability in fourth, six, and eight graders. Applied Psycholinguistics, 9, 247-266.

Carlisle, J. (2000). Awareness of the structure and meaning of morphologically complex words: impact on reading. Reading and Writing: an Interdisciplinary Journal, 12, 169-190.

Carlisle, J., \& Fleming, J. (2003). Lexical processing of morphologically complex words in the elementary years. Scientific Studies of Reading, 7(3), 239-253.

Carlisle, J., Stone, C., \& Katz, L. (2001). The effects of phonological transparency on reading derived words. Annals of dyslexia, 51, 249-274.

Chomsky, C., \& Halle, M. (1968). The sound pattern of English. New York: Harper \& Row.

Colé, P., Marec-Breton, N., Royer, C., \& Gombert, J. (2003). Morphologie des mots et apprentissage de la lecture. Reeducation Orthophonic, 213, 57-60.

Deacon, S., \& Kirby, J. (2004). Morphological Awareness: Just "more phonological"? The roles of morphological and phonological awareness in reading development. Applied Psycholinguistics, 25, 223-238.

Fowler, A., \& Liberman, I. (1995). The role of phonology and orthography in morphological awareness. Em L. Feldman (Org.), Morphological aspects of language processing (pp.157-188). Hillsdale: Lawrence Erlbaum Associates.

Frith, U. (1985). Beneath the surface of developmetal dislexia. Em K. Patterson, M. Coltheart \& J. Marshal (Orgs.), Surface Dislexia (pp. 301-330). London: Lawrence Erlbaum Associates.

Gombert, J. (1992). Metalinguistic Development. Hertfordshire: Harverster Whesheaf.

Gombert, J. (2003). Atividades metalingüística e aquisição da leitura. Em Maluf (org). Metalinguagem e Aquisição da escrita. São Paulo: Casa do Psicólogo.

Goswami, U., \& Bryant, P. (1990). Phonological Skills and Learning to Read. London: Lawrence Erlbaun Associates.

Guaraldo, C. (2006). A contribuição da Consciência fonológica e dos processos subjacentes à velocidade de nomeação para o desenvolvimento da leitura e da escrita no português brasileiro. Dissertação de Mestrado, Universidade Federal de Minas Gerais, Minas Gerais.

Guimarães, S. (2003). Dificuldades no desenvolvimento da lectoescrita: o papel das habilidades metalinguísticas. Psicologia: Teoria e Pesquisa, 19 (1), p. 33-45.

Lehtonen, A. \& Bryant, P. (2005). Active players or just passive bystanders? The role of morphemes in spelling development in a transparent orthography. Applied psycholinguistics, 26(2), pp.137155. 
Maluf, M. R., \& Barrera, S. (1997). Consciência fonológica e linguagem escrita em pré-escolares. Psicologia: Reflexão e Crítica, 10(1), 125-145.

Mann, V. (2000). Introduction to special issue on morphology and the acquisition of alphabetic writing systems. Reading and Writing: an Interdisciplinary Journal, 12, 143-147.

Marec-Breton, N., \& Gombert, J. (2004). A dimensão morfológica nos principais modelos de aprendizagem da leitura. Em M. R. Maluf (Org.), Psicologia Educacional: Questões Contemporâneas (pp. 105-122). São Paulo: Casa do Psicólogo.

Marsh, G., Friedman, M., Welsh, V., \& Desberg, P. (1980). The development of strategies in spelling. Em U. Frith (Org.), Cognitive processes in spelling (pp. 339-353). London: Academic Press.

Mota, M. (1996). Children's role of grammatical rules in spelling. Tese de doutorado não publicada, departamento de Psicologia Experimental, Universidade de Oxford, Inglaterra.

Mota, M., Aníbal, L., \& Lima, S. (no prelo). A Morfologia Derivacional Contribui para a Leitura e Escrita no Português? Psicologia: Reflexão e Critica.

Nagy, W., Berninger, V., \& Abbot, R. (2003). Relationship of morphology and other language skills to literacy skills in at-risk second-grade and at risk fourth-grade writers. Journal of educational psychology, 95(4), 730-742.

Nagy, W., Berninger, V., \& Abbot, R. (2006). Contributions of morphology beyond phonology to literacy outcome of upper elementary and middle-school students. Journal of Educational Psychology, 98(1), 134-147.

Nunes, T., \& Bryant, P. (2006). Improving literacy by teaching morphemes. London: Routledge.

Nunes, T., Bryant, P., \& Bindman, M. (1997). Morphological Spelling Strategies: Developmental Stages and Processes. Developmental Psychology, 33(4), 637-649.
Plaza, M., \& Cohen, H. (2003). The interaction between phonological processing, syntactic awareness, and naming speed in the reading and spelling performance of first-grade children. Brain and Cognition, 53, 257-292.

Plaza, M., \& Cohen, H. (2004). Predictive influence of phonological processing, morphological/syntactic skill, and naming speed on spelling performance. Brain and Cognition, 55, 368-373.

Queiroga, B., Lins, M., \& Pereira, M. (2006). Conhecimento morfossintático e ortografia em crianças do ensino fundamental. Psicologia: Teoria e Pesquisa, 22(1), 95-99.

Rego, L., \& Buarque, L. (1997). Consciência sintática, consciência fonológica e aquisição de regras ortográficas. Psicologia: Reflexão e Crítica, 10(2), 199-217.

Santos, A. A. A. (1996). A influência da consciência fonológica na aquisição da leitura e da escrita. In F. F. Sisto, G. C. Oliveira, L. D.. T. Fini, M. T. C. C. Souza, \& R. P. Brenelli (Eds.). Atuação psicopedagógica e aprendizagem escolar (pp. 213-247). Petrópolis: Vozes.

Santos, A. A. A. (2003). A influência da consciência fonológica na aquisição da leitura e escrita. Em F. Sisto, G. Oliveira, L. Fini, M. T. Souza \& R. Brenelli (Orgs.), Atuação psicopedagógica em aprendizagem escolar (pp. 213-241). Petrópolis: Vozes.

Sterling, C. (1992). Introduction to the psychology of spelling. In C. Sterling \& C. Robson (orgs.). Psychology, Spelling \& Education.(pp. 1-15). Adelaide: Multilingual Matters.

Sterling, C. (2001). Introduction to the psichology of spelling. Em C. Sterling \& C. Robson (Orgs.), Psychology, Spelling \& Education (pp. 1-15). Clevedon: Multilingual Matters.

Recebido em: 12/03/2007

Revisado em: 18/08/2008

Aprovado em: 27/08/2008

\section{Sobre a autora}

Márcia Elia da Mota (mmotapsi@terra.com.br) - Universidade Federal de Juiz de Fora, Departamento de Psicologia, Doutora em Psicologia pela Universidade de Oxford - Inglaterra

Universidade Federal de Juiz de Fora - ICH - Departamento de Psicologia

Campus Universitário Martelos - 36036900 Juiz de Fora - MG 
